\title{
Long-Term Nicorandil Therapy Improves Cardiac Sympathetic Nerve Activity After Reperfusion Therapy in Patients with First Acute Myocardial Infarction
}

\author{
Shu Kasama ${ }^{1}$, Takuji Toyama ${ }^{1}$, Hiroyuki Sumino ${ }^{2}$, Hisao Kumakura ${ }^{2}$, Yoshiaki Takayama ${ }^{2}$, Shuichi Ichikawa ${ }^{2}$, \\ Tadashi Suzuki ${ }^{1}$, and Masahiko Kurabayashi ${ }^{1}$ \\ ${ }^{1}$ Department of Cardiovascular Medicine, Gunma University School of Medicine, Maebashi, Japan; and ${ }^{2}$ Cardiovascular Hospital of \\ Central Japan, Gunma, Japan
}

\begin{abstract}
Nicorandil, an adenosine triphosphate-sensitive potassium channel opener, reduces plasma norepinephrine concentration in patients with ischemic heart disease. However, long-term effects on cardiac sympathetic nerve activity (CSNA) as evaluated by ${ }^{123}$ I-metaiodobenzylguanidine (MIBG) scintigraphy have not been determined for patients with acute myocardial infarction (AMI). Methods: We studied 40 patients with their first AMI who were treated with intravenous nicorandil before and after primary coronary angioplasty. After suspension of the initial intravenous nicorandil treatment, 20 patients were randomized to receive oral nicorandil ( $15 \mathrm{mg} / \mathrm{d}$ ) (group A) and the other 20 patients received a placebo (group $B$ ). All patients were also treated with an angiotensin-converting enzyme (ACE) inhibitor or $\beta$-blockers. The delayed heart-to-mediastinum count ratio ( $\mathrm{H} / \mathrm{M}$ ratio), delayed total defect score (TDS), and washout rate (WR) were determined from ${ }^{123} \mathrm{I}-\mathrm{MIBG}$ scintigraphy $3 \mathrm{wk}$ and 6 mo after angioplasty. The left ventricular (LV) end-diastolic volume (EDV), LV endsystolic volume (ESV), and LV ejection fraction (EF) were determined by contrast left ventriculography, whereas plasma procollagen type III amino-terminal peptide (PIIINP) concentrations were also measured at the same time points. Results: Three weeks after angioplasty, TDS, H/M ratios, WR, LVEDV, LVESV, and LVEF were similar in both groups. After $6 \mathrm{mo}$, all of these parameters had improved in both groups. However, the extent of change in TDS was $-9 \pm 6$ in group $A$ and $-5 \pm 6$ in group $\mathrm{B}(P<0.05)$, whereas that in the $\mathrm{H} / \mathrm{M}$ ratio was $0.15 \pm$ 0.13 and $0.07 \pm 0.11(P<0.05)$ and that in the WR was $-12 \% \pm 8 \%$ and $-5 \% \pm 11 \%(P<0.05)$. The extent of change in LVEDV, LVESV, and LVEF in group A tended to exceed that in group $B$, but these changes were not statistically significant. We found significant correlations between the percent change in PIIINP and that of TDS from baseline to 6 mo in group A $(r=0.456, P<0.05)$. Conclusion: Long-term nicorandil therapy can be more beneficial for CSNA and LV remodeling than shortterm therapy in patients with AMI.
\end{abstract}

Received Apr. 24, 2007; revision accepted Jul. 11, 2007.

For correspondence or reprints contact: Shu Kasama, MD, Department of Cardiovascular Medicine, Gunma University School of Medicine, 3-39-15,

Showa-machi, Maebashi, Gunma 371-0034, Japan.

E-mail: s-kasama@bay.wind.ne.jp

COPYRIGHT @ 2007 by the Society of Nuclear Medicine, Inc.
Key Words: ${ }^{123}$-metaiodobenzylguanidine; myocardial infarction; ion channels

J Nucl Med 2007; 48:1676-1682

DOI: 10.2967/jnumed.107.043075

I schemic preconditioning is a cardioprotective phenomenon whereby short periods of myocardial ischemia result in myocardial resistance to the harmful effects of subsequent episodes of prolonged ischemia (1). Several studies suggest that this preconditioning effect is attributable to the activation of adenosine triphosphate-sensitive potassium (K-ATP) channels $(2,3)$.

Nicorandil ( $N$-(2-hydroxyethyl)-nicotinamide nitrate; Chugai), a drug with both nitrate-like and K-ATP channelactivating properties (4), has been reported to have preconditioning effects in the ischemic myocardium (5). The Impact of Nicorandil in Angina (IONA) study, a completed randomized placebo control trial, clearly demonstrated significant reductions in major coronary events after nicorandil administration to patients with stable angina (6). Moreover, this agent has been shown to be effective in the treatment of patients with acute myocardial infarction (AMI) $(7,8)$.

Myocardial imaging with ${ }^{123}$ I-metaiodobenzylguanidine (MIBG), a norepinephrine analog, is a useful tool for detecting abnormalities of the myocardial adrenergic nervous system in patients with AMI (9). Myocardial risk area and cardiac ${ }^{123}$ I-MIBG defect size are correlated in patients undergoing reperfusion therapy for acute coronary syndromes (10). On the basis of cardiac ${ }^{123}$ I-MIBG scintigraphic studies, many investigations have suggested that cardioprotective treatment can improve cardiac sympathetic nerve activity (CSNA) in patients with heart disease (11-22). However, to our knowledge, no reports discuss the changes in cardiac ${ }^{123} \mathrm{I}-$ MIBG scintigraphic findings in response to long-term administration of nicorandil in patients with AMI, although we 
previously reported that intravenous nicorandil improves CSNA after reperfusion therapy in such patients (18).

In the present study, we compared the effects of long-term and short-term nicorandil therapy on CSNA after reperfusion therapy in patients with AMI.

\section{MATERIALS AND METHODS}

\section{Study Population}

We prospectively studied 52 patients with their first AMI. Admission criteria included prolonged chest pain $(>30 \mathrm{~min})$, an electrocardiographic ST segment elevation of $>2 \mathrm{mV}$ in 2 or more leads, successful reperfusion therapy within $6 \mathrm{~h}$ of the onset, and $>3$-fold increase in serum creatine phosphokinase activities. Patients were excluded for the following reasons: age $>80 \mathrm{y}$, cardiogenic shock or hypotension (systolic blood pressure $<90$ $\mathrm{mm} \mathrm{Hg}$ ), renal failure, liver dysfunction, prior myocardial infarction, or significant stenosis of the infarct nonrelated coronary artery. Patients with diabetes or glucose intolerance were also excluded from the study. Glucose intolerance was defined as fasting glucose concentrations of $>110 \mathrm{mg} / \mathrm{dL}$ and $<126 \mathrm{mg} / \mathrm{dL}$ or glucose concentrations of $>140 \mathrm{mg} / \mathrm{dL}$ and $<200 \mathrm{mg} / \mathrm{dL}$ at $2 \mathrm{~h}$ after $75-\mathrm{g}$ glucose loading.

After establishing the diagnosis of AMI, we injected a bolus of nicorandil (4 mg). All patients underwent cardiac catheterization with the femoral approach after an injection of $100 \mathrm{U} / \mathrm{kg}$ of heparin. The infarct-related artery was visualized with contrast injections. Patients with persistent occlusion of the infarct-related vessel underwent percutaneous coronary intervention (PCI) by standard techniques. Patients unable to achieve $>50 \%$ patency or Thrombolysis in Myocardial Infarction (TIMI) flow grade 3 (23) were excluded from this study. After PCI, all patients received aspirin, ticlopidine, angiotensin-converting enzyme (ACE) inhibitors or $\beta$-blocker.

Immediately after hemodynamic stability had been ensured and soon after arrival at the coronary care unit, all patients received a continuous infusion of nicorandil at $4 \mathrm{mg} / \mathrm{h}$. Intravenous nicorandil was continuously infused for $>48 \mathrm{~h}$. The study was approved by the ethics review board of the Cardiovascular Hospital of Central Japan, and written informed consent was obtained from all patients.

\section{Study Protocol}

In this prospective randomized study (double-blind, 1:1 ratio), after suspension of intravenous nicorandil administration, 26 patients were randomized to receive oral nicorandil $(15 \mathrm{mg} / \mathrm{d}$ ) (group A) and the other 26 patients received a placebo (group B). Followup coronary angiography (CAG) and contrast left ventriculography (LVG) (right anterior oblique $30^{\circ}$ ) were performed $3 \mathrm{wk}$ after PCI. Left ventricular (LV) end-diastolic volume (EDV), LV end-systolic volume (ESV), and LV ejection fraction (EF) were calculated by the area-length method. These measurements were performed by an independent observer who was unaware of each patient's clinical data. We also performed ${ }^{123}$ I-MIBG scintigraphy and measured plasma procollagen type III amino-terminal peptide (PIIINP) concentrations at the same time points ( $3 \mathrm{wk}$ after PCI).

After 6 mo of treatment, we repeated a series of examinations (CAG, LVG, ${ }^{123}$ I-MIBG scintigraphy, and measurement of plasma PIIINP concentration). Patients with significant restenosis of the culprit lesion were excluded from the study.

\section{I-MIBG Imaging}

The ${ }^{123}$ I-MIBG imaging method has been described previously (19-21). ${ }^{123}$ I-MIBG was obtained from a commercial source (Fuji Film RI Pharma Co. Ltd.). Patients were intravenously injected ${ }^{123} \mathrm{I}-\mathrm{MIBG}(111 \mathrm{MBq}$ ) while in the supine position. At $15 \mathrm{~min}$ and at $4 \mathrm{~h}$ after the injection, static data were acquired in the anterior view with a single-head $\gamma$-camera (Millennium MPR; GE Healthcare) equipped with a low-energy, general-purpose, parallel-hole collimator. Static images on a $128 \times 128$ matrix were collected for 5 min with a $20 \%$ window centered on $159 \mathrm{keV}$, corresponding to the ${ }^{123}$ I photopeak. After the static planar images were acquired, SPECT images were obtained. The camera was rotated over $180^{\circ}$ from the $45^{\circ}$ right anterior oblique position to the $45^{\circ}$ left posterior oblique position in 32 views with an acquisition time of $40 \mathrm{~s}$ per view. Scans were acquired in a $64 \times 64$ matrix by a filtered backprojection method for reconstruction.

The heart-to-mediastinum count ratio (H/M ratio) was determined from the anterior planar delayed ${ }^{123}$ I-MIBG image. The washout rate (WR) was calculated using the following formula: $\{([\mathrm{H}]-[\mathrm{M}])$ early $-([\mathrm{H}]-[\mathrm{M}])$ delayed $\} /([\mathrm{H}]-[\mathrm{M}])$ early $\times 100$ $(\%)$, where $[\mathrm{H}]=$ mean counts/pixel in the left ventricle and $[\mathrm{M}]=$ mean counts/pixel in the upper mediastinum. In this study, time decay was not corrected for the calculation of WR.

The delayed myocardial SPECT images of each patient were divided into 17 segments as recommended by the American Heart Association (24). Regional tracer uptake was assessed semiquantitatively using a 5-point scoring system $(0=$ normal uptake, $1=$ mildly reduced uptake, $2=$ moderately reduced uptake, $3=$ significantly reduced uptake, $4=$ no uptake). The total defect score (TDS) was calculated as the sum of all defect scores.

\section{Plasma PIIINP Concentrations}

Blood samples were collected from an antecubital vein after a rest period of at least $20 \mathrm{~min}$. PIIINP plasma levels were measured by a specific immunoradiometric assay using a commercial kit (CIS Bio International).

\section{Serial Changes Between First and Second Scintigraphic and Contrast Left Ventriculographic Parameters and Plasma PIIINP Concentrations}

Changes between the first ( $3 \mathrm{wk})$ and second $(6 \mathrm{mo}){ }^{123} \mathrm{I}-\mathrm{MIBG}$ scintigraphic parameters (TDS, H/M ratio, and WR), contrast left ventriculographic parameters (EDV, ESV, and LVEF), and plasma PIIINP concentrations were calculated using the following formula: $\delta-(\mathrm{X})=[(\mathrm{X})$ value after $6 \mathrm{mo}]-[$ baseline value of $(\mathrm{X})]$, where $(X)={ }^{123}$ I-MIBG scintigraphic and contrast left ventriculographic parameters or plasma PIIINP concentrations.

\section{Data Analysis and Statistics}

Statistical analysis was performed by using SPSS 12.0 for Windows (SPSS Inc.). Numeric results are expressed as the mean \pm SD. Comparisons of baseline categoric data between the 2 groups were performed by the 1 -sided $\chi^{2}$ contingency table method, whereas differences between continuous variables were evaluated using the unpaired $t$ test. In patients undergoing repeated assessments, changes from baseline were evaluated within each treatment group using a paired $t$ test and between the 2 groups using 2-way ANOVA. The relationship between continuous variables was determined by linear regression analysis. In all analyses, $P<0.05$ was deemed statistically significant. 
RESULTS

\section{Clinical Characteristics}

In group A, 1 patient experienced a cerebral infarction, 2 patients were excluded because of restenosis emerging 6 mo after angioplasty at the culprit lesion, and 3 patients were excluded because the follow-up examinations was not completely obtained. In group B, 1 patient died of congestive heart failure 3 mo after admission, another patient was excluded because of restenosis, and 4 patients were excluded because the follow-up examinations were not completely obtained. Thus, 40 of 52 patients (29 men, 11 women; mean age, $63 \pm 11 \mathrm{y}$; range, 44-79 y) enrolled in the trial completed the entire protocol (group A, $n=20$; group $\mathrm{B}, n=20$ ). No significant differences were observed in clinical characteristics or cardiac medication between the subjects in the 2 groups on their entry into the study (Table 1). The mean duration of intravenous nicorandil administration was $54 \pm 16 \mathrm{~h}$ (range, 48-96 h) in group $\mathrm{A}$; the mean duration was $56 \pm 15 \mathrm{~h}$ (range, 48-96 h) in group $\mathrm{B}$. Moreover, at baseline, ${ }^{123}$ I-MIBG scintigraphic and contrast left ventriculographic parameters and plasma levels of PIIINP were similar for both groups (Table 2). None of the patients changed baseline cardiac drugs during the followup period. The mean dose of enalapril was $7.2 \pm 3.4 \mathrm{mg} / \mathrm{d}$ in group A versus $7.5 \pm 2.5 \mathrm{mg} / \mathrm{d}$ in group B. The mean

TABLE 1

Clinical Characteristics of Patients

\begin{tabular}{lccc}
\hline \multicolumn{1}{c}{ Characteristic } & $\begin{array}{c}\text { Group A } \\
(n=20)\end{array}$ & $\begin{array}{c}\text { Group B } \\
(n=20)\end{array}$ & $P$ \\
\hline Age (y) & $63 \pm 11$ & $65 \pm 10$ & 0.551 \\
Sex & & & 0.723 \\
$\quad$ Male & $14(70)$ & $15(75)$ & \\
Female & $6(30)$ & $5(25)$ & \\
Culprit coronary artery & & & \\
LAD & $10(50)$ & $10(50)$ & 1.000 \\
RCA & $8(40)$ & $7(35)$ & 0.744 \\
LCX & $2(10)$ & $3(15)$ & 0.633 \\
History of stroke & $2(10)$ & $2(10)$ & 1.000 \\
Diabetes mellitus & $0(0)$ & $0(0)$ & 1.000 \\
Hypertension & $11(55)$ & $12(60)$ & 0.749 \\
Hyperlipidemia & $9(45)$ & $10(50)$ & 0.751 \\
Current smoker & $14(70)$ & $15(75)$ & 0.723 \\
Recanalization time (h) & $3.6 \pm 1.2$ & $3.7 \pm 1.5$ & 0.817 \\
Stent implantation & $18(90)$ & $17(85)$ & 0.633 \\
Peak CPK (IU/L) & $2,275 \pm 1,215$ & $2,366 \pm 1,542$ & 0.837 \\
Pharmacotherapy & & & \\
ACE inhibitor & $100(100)$ & $100(100)$ & 1.000 \\
$\beta$-Blocker & $16(80)$ & $15(75)$ & 0.705 \\
Calcium antagonist & $5(25)$ & $4(20)$ & 0.705 \\
Loop diuretic & $2(10)$ & $4(20)$ & 0.376 \\
Spironolactone & $6(30)$ & $7(35)$ & 0.736 \\
& & & \\
& &
\end{tabular}

$L A D=$ left anterior descending coronary artery; $R C A=$ right coronary artery; LCX = left circumflex coronary artery; CPK = creatine phosphokinase.

Values are mean \pm SD or number (\%).
TABLE 2

Baseline ${ }^{123}$ I-MIBG Scintigraphic and Left

Ventriculographic Parameters and Plasma PIIINP Concentrations of Both Groups

\begin{tabular}{lccc}
\hline \multicolumn{1}{c}{ Parameter } & $\begin{array}{c}\text { Group A } \\
(n=20)\end{array}$ & $\begin{array}{c}\text { Group B } \\
(n=20)\end{array}$ & $P$ \\
\hline 123I-MIBG scintigraphy & & & \\
TDS & $28 \pm 7$ & $31 \pm 7$ & 0.183 \\
H/M ratio & $1.96 \pm 0.36$ & $1.88 \pm 0.33$ & 0.468 \\
WR (\%) & $44 \pm 11$ & $46 \pm 10$ & 0.551 \\
Left ventriculography & & & \\
LVEDV (mL) & $82 \pm 54$ & $87 \pm 60$ & 0.783 \\
LVESV (mL) & $40 \pm 31$ & $44 \pm 37$ & 0.713 \\
LVEF $(\%)$ & $51 \pm 9$ & $50 \pm 13$ & 0.779 \\
Plasma PIIINP $(\mathrm{U} / \mathrm{mL})$ & $0.67 \pm 0.15$ & $0.69 \pm 0.19$ & 0.714
\end{tabular}

LVEDV = LV end-diastolic volume; LVESV = LV end-systolic volume; LVEF $=\mathrm{LV}$ ejection fraction.

Values are mean \pm SD.

dose of perindopril was $2.3 \pm 1.3 \mathrm{mg} / \mathrm{d}$ in group A versus $2.5 \pm 1.0 \mathrm{mg} / \mathrm{d}$ in group B. The mean dose of carvedilol was $11 \pm 5 \mathrm{mg} / \mathrm{d}$ in group A versus $12 \pm 6 \mathrm{mg} / \mathrm{d}$ in group B. The mean dose of furosemide was $30 \pm 14 \mathrm{mg} / \mathrm{d}$ in group A versus $35 \pm 19 \mathrm{mg} / \mathrm{d}$ in group B. Spironolactone doses were a mere $25 \mathrm{mg} / \mathrm{d}$ in both groups.

\section{Comparison of Cardiac ${ }^{123}$ I-MIBG Scintigraphic Findings at 2 Weeks and at 6 Months After Treatment}

Figure 1 provides a summary of TDS, H/M ratios, and WR values. In both groups, TDS decreased significantly after 6 mo relative to baseline values. However, the $\delta$-TDS in group A was significantly lower than that in group B. In both groups, $\mathrm{H} / \mathrm{M}$ ratios increased significantly after 6 mo from baseline values. However, $\delta-H / M$ ratios in group $\mathrm{A}$ were significantly higher than those in group B. Finally, although the WR in both groups decreased significantly after 6 mo relative to baseline values, the $\delta$-WR in group A was significantly lower than that in group B.

\section{Comparison of Contrast Left Ventriculographic Findings at 3 Weeks and at 6 Months After Treatment}

Table 3 provides a summary of LVEDV, LVESV, and LVEF. In group A, LVEDV and LVESV decreased significantly and LVEF increased significantly after 6 mo relative to baseline values. In group B, only LVESV decreased significantly after 6 mo. The extent of change in LVEDV, LVESV, and LVEF in group A tended to be more favorable than that in group B, but these changes were not statistically significant.

\section{Comparison of Plasma PIIINP Concentrations at 3 Weeks and at 6 Months After Treatment}

Table 3 provides plasma PIIINP concentrations. In group A, baseline plasma PIIINP was not significantly different after 6 mo of treatment. In group B, this parameter tended to increase after 6 mo from baseline values, but the 


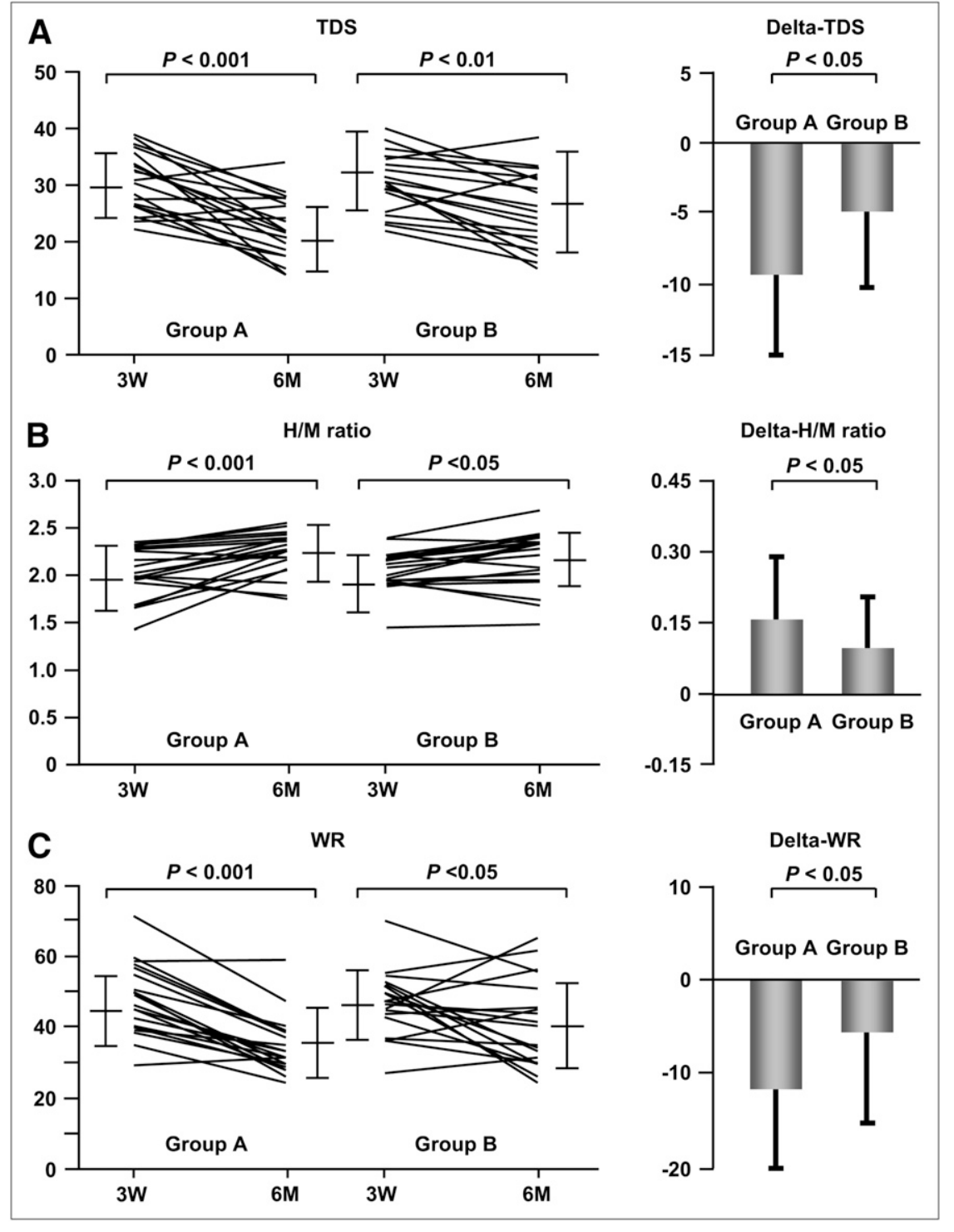

FIGURE 1. Comparison of cardiac ${ }^{123 \mid-}$ MIBG scintigraphic findings for TDS (A), $\mathrm{H} / \mathrm{M}$ ratio (B), and WR (C) in 2 groups. $3 \mathrm{~W}=$ after $3 \mathrm{wk}$ of therapy; $6 \mathrm{M}=$ after 6 mo of therapy. differences were not significant. However, $\delta$-plasma PIIINP in group A was significantly lower than that in group B.

\section{Relationship Between Percent Change of PIIINP and TDS Before and After Treatment}

We found significant correlations between the percent change in plasma PIIINP concentrations and that of TDS evaluated by ${ }^{123}$ I-MIBG scintigraphy from the baseline to 6 mo (Fig. 2) in group A ( $r=0.456, P<0.05)$. In contrast, we found no relationship between these parameters in group $\mathrm{B}(r=0.336, P=0.196)$.

\section{Relationship Between Percent Change of LVEF and TDS Before and After Treatment}

There was a significant correlation between the percent change of contrast left ventriculographic LVEF and that of TDS evaluated by ${ }^{123}$ I-MIBG scintigraphy from the baseline to 6 mo (Fig. 3) in group A $(r=-0.580, P<0.01)$. In contrast, there was no relationship between these parameters in group $\mathrm{B}(r=-0.316, P=0.178)$.

\section{DISCUSSION}

The major finding of this present study is that long-term administration of nicorandil improves CSNA and prevents LV remodeling more effectively than short-term therapy after reperfusion therapy in patients with AMI.

Nicorandil has been reported to reduce infarct size and improve recovery from postischemic contractile dysfunction when administered intravenously during occlusion or reperfusion (7). Several potential mechanisms have been proposed for nicorandil's cardioprotective effects: (a) reduction before and after load (25), (b) improved myocardial perfusion (26), (c) pharmacologic preconditioning (27), (d) prevention of $\mathrm{Ca}^{2+}$ overload by opening ATP-sensitive potassium channels (28), and (d) free radical scavenging and neutrophil-modulating properties (29). Although the 
TABLE 3

Changes of LV Volume, LV Ejection Fraction, and Plasma PIIINP Concentration of Patients in Both Groups

\begin{tabular}{|c|c|c|c|c|c|c|}
\hline \multirow[b]{2}{*}{ Parameter } & \multicolumn{3}{|c|}{ Group A } & \multicolumn{3}{|c|}{ Group B } \\
\hline & $3 \mathrm{wk}$ & $6 \mathrm{~m}$ & $\delta$ & $3 \mathrm{wk}$ & $6 \mathrm{~m}$ & $\delta$ \\
\hline $\begin{array}{l}\text { Left ventriculography } \\
\text { LVEDV (mL) } \\
\text { LVESV (mL) } \\
\text { LVEF (\%) } \\
\text { Plasma PIIINP (U/mL) }\end{array}$ & $\begin{array}{c}82 \pm 54 \\
40 \pm 31 \\
51 \pm 9 \\
0.67 \pm 0.15\end{array}$ & $\begin{aligned} 70 & \pm 44^{\star} \\
29 & \pm 22^{\star} \\
59 & \pm 12^{\star} \\
0.66 & \pm 0.15\end{aligned}$ & $\begin{aligned}-12 & \pm 16 \\
-10 & \pm 12 \\
9 & \pm 10 \\
-0.01 & \pm 0.05\end{aligned}$ & $\begin{array}{c}87 \pm 60 \\
44 \pm 37 \\
50 \pm 13 \\
0.69 \pm 0.19\end{array}$ & $\begin{array}{c}78 \pm 52 \\
36 \pm 23^{\star} \\
54 \pm 11 \\
0.75 \pm 0.20\end{array}$ & $\begin{aligned}-9 & \pm 17 \\
-8 & \pm 15 \\
5 & \pm 11 \\
0.06 & \pm 0.08^{\dagger}\end{aligned}$ \\
\hline $\begin{array}{l}{ }^{*} P<0.05 \text { vs. baseline. } \\
{ }^{\dagger} P<0.05 \text { vs. group } A . \\
\text { LVEDV }=\text { LV end-diasto } \\
\text { terminal peptide. } \\
\text { Values are mean } \pm \mathrm{SD} .\end{array}$ & Iolume; LVESI & LV end-systol & lume; LVEF = & jection fractio & IIINP $=$ proc & en type III amino- \\
\hline
\end{tabular}

mechanisms underlying nicorandil's protection of the myocardium during acute ischemic injury have been extensively reported, little is known about the effects of long-term treatment with nicorandil in infarction-induced LV dilatation and contraction. The extent of changes in LV volume and function have been shown to be associated with short- and long-term prognosis in patients with heart failure caused by ischemic cardiomyopathy (30). For this reason, increasing effort has been directed toward pharmacologic attenuation of LV remodeling after myocardial infarction. This study found that long-term nicorandil therapy significantly improved LV volume and cardiac function compared with short-term therapy.

An analog of the adrenergic neuron-blocking agent guanethidine, ${ }^{123}$ I-MIBG is thought to use the same mechanism of myocardial uptake, storage, and release as norepi-

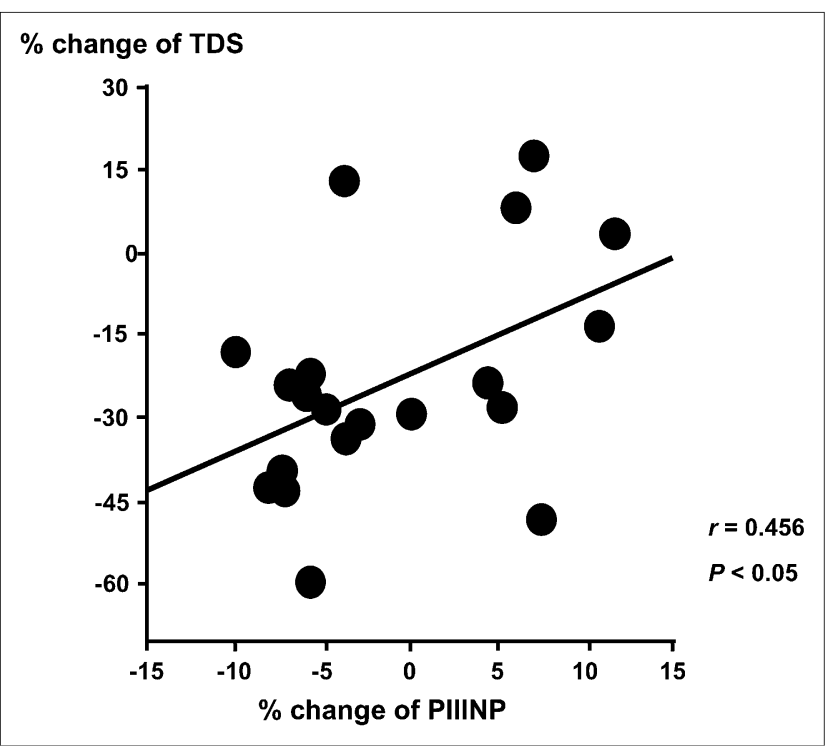

FIGURE 2. Correlation between percent change in plasma PIIINP concentrations and that of TDS evaluated by ${ }^{123} \mathrm{I}-\mathrm{MIBG}$ scintigraphy from baseline to $6 \mathrm{mo}$ after long-term nicorandil therapy. nephrine (31). Myocardial norepinephrine concentrations and ${ }^{123}$ I-MIBG uptake have been shown to correlate in the failing human heart (32). Moreover, several reports suggest that cardiac ${ }^{123}$ I-MIBG scintigraphic findings are closely associated with LV dilatation in patients (9) and in animal models (33) of myocardial infarction. Sakata et al. (9) have reported that cardiac sympathetic nerve abnormalities, as assessed by ${ }^{123}$ I-MIBG images, contribute to LV remodeling after reperfusion therapy in patients with acute coronary syndrome. On the other hand, Ogino et al. (34) report that nicorandil inhibits CSNA evaluated by measuring plasma norepinephrine concentration. However, no reports on cardiac ${ }^{123}$ I-MIBG scintigraphy and left ventriculography address the effects of long-term nicorandil therapy in patients with AMI. In our study, we used ${ }^{123}$ I-MIBG scintigraphy and contrast left ventriculography to examine whether long-term

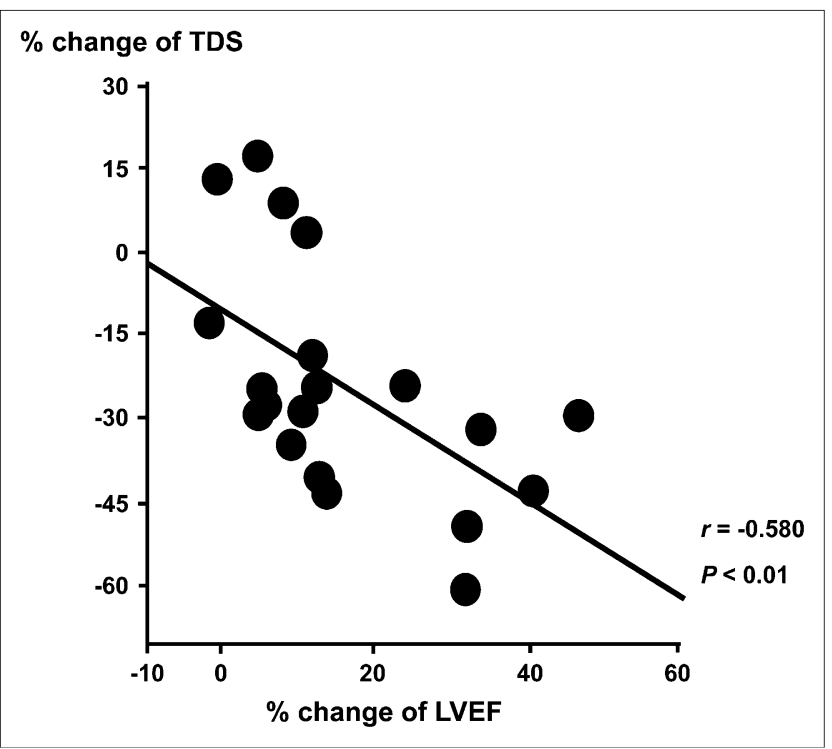

FIGURE 3. Correlation between percent change in contrast left ventriculographic LVEF and that of TDS evaluated by ${ }^{123}$ IMIBG scintigraphy from baseline to $6 \mathrm{mo}$ after long-term nicorandil therapy. 
nicorandil therapy improves CSNA and attenuates LV remodeling. We found that such treatment after reperfusion therapy improved parameters in patients with AMI.

Plasma PIIINP concentrations may constitute a biochemical marker for myocardial fibrosis or LV remodeling in patients with AMI $(35,36)$. Tsutamoto et al. (37) have also discussed a positive correlation between the plasma PIIINP concentrations and LV volumes in the failing human heart. In the present study, plasma PIIINP increased after shortterm nicorandil therapy, whereas no significant change in this parameter was observed after long-term therapy. Moreover, we found a significant correlation between the percent change in plasma PIIINP concentrations and that of defect scores evaluated by ${ }^{123}$ I-MIBG scintigraphy from baseline to 6 mo after long-term nicorandil therapy in patients with AMI. In addition to attenuating myocardial fibrosis, longterm administration of nicorandil may also improve CSNA after reperfusion therapy in patients with AMI. Further study will be required to confirm this hypothesis.

One limitation of the present study was the relatively small number of patients with AMI enrolled. Despite the short-term therapy group, the study design also omitted a placebo group. In the future, we need to examine the effects of nicorandil on CSNA and LV parameters using larger numbers of patients and to compare the effects of the longterm nicorandil therapy group with the results of a placebo group.

Currently, many independent reports from different centers around the world support the idea that ${ }^{123} \mathrm{I}-\mathrm{MIBG}$ myocardial scintigraphy provides useful information for assessing patients with heart disease. This imaging modality appears valuable in predicting prognoses and for estimating the long-term efficacy of therapy. However, quantitative ${ }^{123}$ I-MIBG parameters differ between institutions and between instruments, and this tracer is not widely available. For these reasons, cardiac ${ }^{123}$ I-MIBG has yet to achieve broad clinical acceptance, and the evidence supporting the clinical value of this imaging technique remains inadequate. We believe multicenter studies are needed to establish the efficacy of this imaging modality.

\section{CONCLUSION}

Six months of long-term nicorandil therapy led to significant improvements in TDS, H/M ratio, and $\mathrm{WR}$, compared with short-term therapy in patients with AMI, as determined by ${ }^{123}$ I-MIBG scintigraphy. Long-term nicorandil therapy also produced results for cardiac function and LV volumes superior to those found for short-term therapy. The study also found significant correlation between percent changes in plasma PIIINP concentrations and those of TDS from the baseline to 6 mo after long-term nicorandil therapy in patients with AMI. These findings indicate that long-term nicorandil therapy can be more beneficial for CSNA and LV remodeling than short-term therapy after reperfusion therapy in patients with AMI.

\section{REFERENCES}

1. Murry CE, Jennings RB, Reimer KA. Preconditioning with ischemia: a delay of lethal cell injury in ischemic myocardium. Circulation. 1986;74:1124-1136.

2. Gross GJ, Auchampach JA. Blockade of ATP-sensitive potassium channels prevents myocardial preconditioning in dogs. Circ Res. 1992;70:223-233.

3. Grover GJ, Sleph PG, Dzwonczyk S. Role of myocardial ATP-sensitive potassium channels in mediating preconditioning in the dog heart and their possible interaction with adenosine A1-receptors. Circulation. 1992;86:1310-1316.

4. Taira N. Nicorandil as a hybrid between nitrates and potassium channel activators. Am J Cardiol. 1989;63:18J-24J.

5. Miura T, Kawamura S, Tatsuno H, et al. Ischemic preconditioning attenuates cardiac sympathetic nerve injury via ATP-sensitive potassium channels during myocardial ischemia. Circulation. 2001;104:1053-1058.

6. The IONA Study Group. Effect of nicorandil on coronary events in patients with stable angina: the Impact of Nicorandil in Angina (IONA) randomized trial. Lancet. 2002;359:1269-1275.

7. Ito $\mathrm{H}$, Taniyama $\mathrm{Y}$, Iwakura $\mathrm{K}$, et al. Intravenous nicorandil can preserve microvascular integrity and myocardial viability in patients with reperfused anterior wall myocardial infarction. J Am Coll Cardiol. 1999;33:654-660.

8. Ishii $\mathrm{H}$, Ichimiya $\mathrm{S}$, Kanashiro $\mathrm{M}$, et al. Impact of a single intravenous administration of nicorandil before reperfusion in patients with ST-segmentelevation myocardial infarction. Circulation. 2005;112:1284-1288.

9. Sakata K, Mochizuki M, Yoshida H, et al. Cardiac sympathetic dysfunction contributes to left ventricular remodeling after acute myocardial infarction. Eur J Nucl Med. 2000;27:1641-1649.

10. Matsunari I, Schricke U, Bengel FM, et al. Extent of cardiac sympathetic neuronal damage is determined by the area of ischemia in patients with acute coronary syndromes. Circulation. 2000;101:2579-2585.

11. Takeishi Y, Atsumi H, Fujiwara S, Takahashi K, Tomoike H. ACE inhibition reduces cardiac iodine-123-MIBG release in heart failure. J Nucl Med. 1997;38: 1085-1089.

12. Toyama T, Aihara Y, Iwasaki T, et al. Cardiac sympathetic activity estimated by ${ }^{123}$ I-MIBG myocardial imaging in patients with dilated cardiomyopathy after beta-blocker or angiotensin-converting enzyme inhibitor therapy. $\mathrm{J} \mathrm{Nucl} \mathrm{Med}$. 1999;40:217-223.

13. Kasama S, Toyama T, Kumakura H, et al. Spironolactone improves cardiac sympathetic nerve activity and symptoms in patients with congestive heart failure. J Nucl Med. 2002;43:1279-1285.

14. Kasama S, Toyama T, Kumakura H, et al. Effect of spironolactone on cardiac sympathetic nerve activity and left ventricular remodeling in patients with dilated cardiomyopathy. J Am Coll Cardiol. 2003;41:574-581.

15. Kasama S, Toyama T, Kumakura H, et al. Addition of valsartan to an angiotensinconverting enzyme inhibitor improves cardiac sympathetic nerve activity and left ventricular function in patients with congestive heart failure. J Nucl Med. 2003;44: 884-890.

16. Kasama S, Toyama T, Kumakura H, et al. Effects of intravenous atrial natriuretic peptide on cardiac sympathetic nerve activity in patients with decompensated congestive heart failure. J Nucl Med. 2004;45:1108-1113.

17. Kasama S, Toyama T, Kumakura H, et al. Effects of candesartan on cardiac sympathetic nerve activity in patients with congestive heart failure and preserved left ventricular ejection fraction. J Am Coll Cardiol. 2005;45:661-667.

18. Kasama S, Toyama T, Kumakura H, et al. Effects of nicorandil on cardiac sympathetic nerve activity after reperfusion therapy in patients with first anterior acute myocardial infarction. Eur J Nucl Med Mol Imaging. 2005;32:322-328.

19. Kasama S, Toyama T, Kumakura H, et al. Effects of perindopril on cardiac sympathetic nerve activity in patients with congestive heart failure: comparison with enalapril. Eur J Nucl Med Mol Imaging. 2005;32:964-971.

20. Kasama S, Toyama T, Hatori T, et al. Comparative effects of valsartan with enalapril on cardiac sympathetic nerve activity and plasma brain natriuretic peptide in patients with congestive heart failure. Heart. 2006;92:625-630.

21. Kasama S, Toyama T, Hatori T, et al. Effects of intravenous atrial natriuretic peptide on cardiac sympathetic nerve activity and left ventricular remodeling in patients with first anterior acute myocardial infarction. J Am Coll Cardiol. 2007;49:667-674.

22. Kasama S, Toyama T, Hatori T, et al. Evaluation of cardiac sympathetic nerve activity and left ventricular remodelling in patients with dilated cardiomyopathy on the treatment containing carvedilol. Eur Heart J. 2007;28:989-995.

23. Chesebro JH, Knatterud G, Roberts R, et al. Thrombolysis in Myocardial Infarction (TIMI) Trial, phase I: a comparison between intravenous tissue plasminogen activator and intravenous streptokinase-clinical findings through hospital discharge. Circulation. 1987;76:142-154.

24. Cerqueira MD, Weissman NJ, Dilsizian V, et al. Standardized myocardial segmentation and nomenclature for tomographic imaging of the heart: a statement for healthcare professionals from the Cardiac Imaging Committee of the Council on 
Clinical Cardiology of the American Heart Association. Circulation. 2002;105: 539-542.

25. Krumenacker M, Roland E. Clinical profile of nicorandil: an overview of its hemodynamic properties and therapeutic efficacy. J Cardiovasc Pharmacol. 1992;20: S93-S102.

26. Yoneyama F, Satoh K, Taira N. Nicorandil increases coronary blood flow predominantly by K-channel opening mechanism. Cardiovasc Drugs Ther. 1990; 4:1119-1126.

27. Matsubara T, Minatoguchi S, Matsuo H, et al. Three minute, but not one minute, ischemia and nicorandil have a preconditioning effect in patients with coronary artery disease. J Am Coll Cardiol. 2000;35:345-351.

28. Lopez JR, Jahangir R, Jahangir A, Shen WK, Terzic A. Potassium channel openers prevent potassium-induced calcium loading of cardiac cells: possible implications in cardioplegia. J Thorac Cardiovasc Surg. 1996;112:820-831.

29. Mizumura T, Nithipatikom K, Gross GJ. Effects of nicorandil and glyceryl trinitrate on infarct size, adenosine release, and neutrophil infiltration in the dog. Cardiovasc Res. 1995;29:482-489.

30. Cohn JN, Johnson GR, Shabetai R, et al. Ejection fraction, peak exercise oxygen consumption, cardiothoracic ratio, ventricular arrhythmias, and plasma norepinephrine as determinants of prognosis in heart failure: the V-HeFT VA Cooperative Studies Group. Circulation. 1993;87:VI5-VI16.
31. Wieland DM, Wu J, Brown LE, Mangner TJ, Swanson DP, Beierwaltes WH. Radiolabeled adrenergic neuron-blocking agents: adrenomedullary imaging with [ ${ }^{131}$ I] iodobenzylguanidine. J Nucl Med. 1980;21:349-353.

32. Schofer J, Spielmann R, Schuchert A, Weber K, Schluter M. Iodine-123 meta-iodobenzylguanidine scintigraphy: a noninvasive method to demonstrate myocardial adrenergic nervous system disintegrity in patients with idiopathic dilated cardiomyopathy. J Am Coll Cardiol. 1988;12:1252-1258.

33. Kramer CM, Nicol PD, Rogers WJ, et al. Reduced sympathetic innervation underlies adjacent noninfarcted region dysfunction during left ventricular remodeling. J Am Coll Cardiol. 1997;30:1079-1085.

34. Ogino K, Kinugawa T, Noguchi N, et al. Suppression of sympathetic nervous system activity by nicorandil during exercise. Gen Pharmacol. 1992;23:325-329.

35. Klappacher G, Franzen P, Haab D, et al. Measuring extracellular matrix turnover in the serum of patients with idiopathic or ischemic dilated cardiomyopathy and impact on diagnosis and prognosis. Am J Cardiol. 1995;75:913-918.

36. Host NB, Jensen LT, Bendixen PM, Jensen SE, Koldkjaer OG, Simonsen EE. The aminoterminal propeptide of type III procollagen provides new information on prognosis after acute myocardial infarction. Am J Cardiol. 1995;76:869-873.

37. Tsutamoto T, Wada A, Maeda K, et al. Spironolactone inhibits the transcardiac extraction of aldosterone in patients with congestive heart failure. J Am Coll Cardiol. 2000;36:838-844. 